\title{
Autism Beyond Early Intensive Behavioral Intervention
}

\author{
Rocío Rosales $^{1}$ (I) Erica S. Jowett Hirst ${ }^{2} \cdot$ Yors A. Garcia $^{3} \cdot$ Ruth Anne Rehfeldt $^{4}$
}

Published online: 29 October 2019

(C) Springer Nature Switzerland AG 2019

\begin{abstract}
Autism spectrum disorder (ASD) affects many individuals worldwide. Researchers have identified effective interventions for teaching new skills and reducing challenging behaviors that have resulted in improvements in the lives of individuals with ASD and their families. Namely, assessments and interventions based on the science of behavior analysis have strong empirical support for improving the quality of life of individuals with ASD. Although beneficial, the majority of this research has involved young children, which is not always easily applied to adolescents and adults due to unique characteristics of this population. This special issue addresses the need for research with older individuals with ASD by presenting a variety of papers evaluating behavioral interventions for adolescents and adults and discussing the specific needs related to this population.
\end{abstract}

Keywords Autism spectrum disorder $\cdot$ Adolescents $\cdot$ Adults $\cdot$ Behavioral interventions

The most recent estimates of the prevalence of autism spectrum disorder (ASD) for children living in the USA are about 1 in 59 (Centers for Disease Control and Prevention 2018). Worldwide estimates are reported at about 1 in 160 (World Health Organization 2018), but reports have varied widely across published studies, and the prevalence of ASD in many low- and middle-income countries is unknown. Despite the difficulty in getting a clear estimate, it is evident that the prevalence of ASD continues to increase on a global scale (Hahler and Elsabbagh 2015). Given the well-documented evidence of early intensive behavioral intervention (EIBI) to improve symptomatology of ASD in young children (Lotfizadeh et al. 2018; National Autism Center 2015; Reichow et al. 2018), it is perhaps not surprising that the majority of research related to behavioral assessment and intervention has been focused on younger populations (Howlin et al. 2009; Roth et al. 2014). However, ASD impacts individuals throughout their lifespan, and the estimated number of adolescents and adults with ASD has been on the rise for the last two decades (Gerhardt and Lainer 2011; Vanbergeijk

Rocío Rosales

rocio_rosales@uml.edu

1 University of Massachusetts Lowell, Lowell, MA, USA

2 The Chicago School of Professional Psychology, Dallas, TX, USA

3 The Chicago School of Professional Psychology, Chicago, IL, USA

4 Southern Illinois University Carbondale, Carbondale, IL, USA et al. 2008). Therefore, there is a dire need for research focused specifically on this age group, whose needs are vastly different from those of young children.

The strengths, needs, and challenges of individuals with ASD are idiosyncratic across the lifespan. However, adolescents and young adults present with a variety of unique service needs and challenges as they enter adulthood (Wong et al. 2015). For example, previous reports have documented the link between early language development and subsequent long-term outcomes, yet individuals with ASD continue to present with unique communication needs into adulthood (Howlin and Moss 2012). If speech is not fully developed, there is a need to identify a modality of communication that will transition well with the learner from school to home and into the community, including employment. On that note, adolescents and adults with ASD require services related to employment preparation that does not need to be considered for young or school-aged children (Chen et al. 2015). There is a need to identify skills that will benefit them in employment situations as well as employment opportunities that align with each individual's strengths. Among other groups of people with disabilities, young adults with ASD represent the group with the lowest rate of employment (Hedley et al. 2017). In addition, young adults with ASD who transition to college are faced with new challenges such as casual social interaction with classmates and professors, making and maintaining new friendships, including romantic relationships, deciding whether or not to disclose their disability, self-advocacy, mental health issues (e.g., anxiety, stress, depression), managing intense emotions 
(Elias and White 2018; Volkmar et al. 2017), and managing personal/adaptive and developing leisure skills (Van Hees et al. 2015). In addition, as individuals with ASD grow bigger and stronger than their caregivers, there may be unique difficulties if caregivers are providing day-to-day support for activities of daily living. For adults with ASD who are not their own guardian, personal rights must be considered when selecting habilitation goals (Bannerman et al. 1990). Finally, the unfortunate reality of access to services and supports (Taylor and Seltzer 2011) brings to light the need to train practitioners and other professionals to work specifically with adolescents and young adults with ASD.

The purpose of this special issue is to highlight some of the recent research developments in the field of behavior analysis that cover a wide range of topics that will be relevant to learners with a wide range of abilities. The papers presented in this Special Issue explore topics that range from using technology to teach functional communication skills, decreasing challenging behaviors, assessment and treatment of sleep disturbances, transitioning to college life, dealing with intense emotions, and working to increase the retention of direct support professionals who are tasked with implementing intervention plans.

The first three papers are demonstrations of how evidencebased interventions for establishing language and social skills in children can be adapted to, and made relevant for, adolescents and young adults. Special considerations are outlined in these studies. For example, Bondy (2019) shares important points when considering the use of speechgenerating devices with adolescents and adults, which he suggests may have dual functions for individuals acquiring a functional communication repertoire. The paper includes an overview of studies that appear to overestimate functional outcomes for individuals using speech-generating devices and provides recommendations for clinicians to assure efforts to teach functional communication result in effective outcomes. Next, Gordon and Shillingsburg (2019) give special attention to one of the most common skill-acquisition targets that is incorporated in functional communication programming - teaching learners how to request desired items/activities and/or request removal of aversive stimuli in their environment. This skill is also necessary to request information from a social partner in order to sustain a conversation, which is the focus of this study. The study by Gordon and Shillingsburg (2019) demonstrates an effective procedure that has been used to teach this skill to younger learners. Experimenters taught participants a series of targets for known and unknown social information and demonstrated acquisition and generalization across all participants with the experimenter and a novel social partner. Finally, Walsh et al. (2019) show efficacy of a specific social-skills curriculum with a variety of components that was used to target 31 social communication skills considered necessary for inclusion in school/post-school, community, and employment with six young adults with ASD. All participants increased their social-communication skills and generalization of skills to natural environments.

The next two papers focus on an area that is commonly targeted by practicing behavior analysts: reduction of aberrant or challenging behavior presented by clients under their care. Anderson et al. (2019b) provide an overview of best practice in treatment of severe problem behavior in their discussion of analogue functional analyses (FAs). These analyses identify environmental variables that evoke and maintain aberrant behavior that may interfere with an individual's ability to acquire new adaptive skills. The information from the analyses is used to develop functionbased interventions. In their study, the authors conducted a traditional functional analysis (Iwata et al. 1994) and compared the outcomes to a recent variation of the traditional FA (Interview-Informed Synthesized Contingency Analysis; Hanley et al. 2014). The researchers also developed interventions based on the outcomes of each FA and compared the efficacy of each intervention. Results demonstrated idiosyncratic outcomes for the participants included in the study, indicating a need for further research on this topic specifically in relation to the cost-benefit ratio of conducting standard versus synthesized FAs in adult service settings. A second paper related to reduction of challenging behavior in this population is related to sleep disturbances (van Deurs et al. 2019). Although it is well documented that issues related to sleep are prevalent in the ASD population, there are few studies that have documented effective interventions to address this problem (e.g., Carnett et al. 2019; Sanberg et al. 2018). One area that has received attention is the involvement of the individual with ASD in the intervention process. This study investigated the feasibility of including pre-adolescents and adolescents with ASD as active intervention agents for their comprehensive individualized treatments for sleep problems. Results suggest that the intervention was effective in eliminating sleep disturbance for all participants, and these improvements maintained up to 24 months following the conclusion of the study. These findings highlight the feasibility and benefit of including adolescents with ASD in development and implementation of individualized behavioral intervention for their sleep problems.

The two subsequent papers are related to young adults with ASD who are attending college. The number of students with ASD entering college has grown significantly in the last decade (White et al. 2011). Although access to college-based programs for young adults with ASD have increased in recent years (Anderson et al. 2019a; Vanbergeijk et al. 2008; Zager and Alpern 2010), there is a dearth of published literature on this topic within the field of behavior analysis. In this Special Issue, Hillier et al. 
(2019) present data from a peer-mentoring program designed to improve students' understanding and preparedness for college life, motivation to attend college, and confidence. Mentorship is key to a successful transition into college but can present unique challenges for young adults with ASD who have difficulty making and sustaining friendships. This exploratory study outlines the model of the peer-mentoring program and presents results from 47 participants who followed a 6-week curriculum. Results from a questionnaire administered to participants showed improvements in all areas targeted in the study, although participants continued to report feeling worried about attending college. Qualitative analysis of open-ended questions and interviews with parents alluded to positive outcomes for participants. Feasibility was also indicated. The study provides support for peer mentoring as an effective strategy to facilitate the college transition for those with ASD. A related study by Huffman et al. (2019) focused on a self-monitoring procedure to provide support in the college classroom for young adults with ASD. These authors examined the efficacy of a selfmonitoring application to increase on-task behavior of a postsecondary student with ASD in a large lecture-style introductory course at a public university. Results indicated a functional relation between self-monitoring and ontask behavior (i.e., looking at assigned work on a projector screen, using the assigned materials, taking notes by hand or on a laptop). Implications and social validity related to supporting postsecondary students with ASD using selfmonitoring interventions are discussed.

A recent development in applied-behavior-analysis research is in the application of Acceptance and Commitment Training (ACT) for children and adults with ASD (Brazeau et al. 2017; Maisel et al. 2019). Here, Szabo (2019) compares an ACT intervention to a direct contingency management procedure to improve attendance and rock-climbing performance in adult athletes with ASD. This novel demonstration is just one example of the variability of research in which behavior analysts working directly with individuals with ASD are actively engaged, and adds to the literature on the relationship between physical activity and social functioning in young people with ASD while speaking to the issue of leisure skills that may be difficult to establish for those individuals living with ASD (Reinders et al. 2019). A second paper related to ACT by Hutchinson et al. (2019) evaluated the effects of a brief ACT protocol and behavioral skills training (BST) on the performance of three young adults with ASD during simulated job interviews. Although recent studies have evaluated teaching strategies to improve job interview performance in young adults with ASD (Rosales and Whitlow 2019); the present study focused on covert behaviors that may interfere with job interview process. Given the reported high prevalence of comorbid anxiety and depression in this population (Hollocks et al. 2019), this is a timely topic. Results of the study showed participants made improvements following the ACT intervention, although they all required BST to master the targeted skills. Together, these two papers provide support for the use of ACT interventions that could help to address behavioral inflexibility experienced by adolescents and adults with ASD and improve their overall well-being.

Finally, the closing paper by Reid (2019) is focused upon effective staff training to support adults with ASD. When individuals with ASD transition to a residential or day program for adults with developmental disabilities, they will ideally receive support from staff within these human-service agencies that are highly trained to provide quality services for the individuals under their care. Unfortunately, the likelihood of burnout and high turnover in agencies that provide services and support to individuals who also present with severe challenging behavior and/or limited adaptive or independentliving skills has been well documented in prior research (Mutkins et al. 2011; Rose et al. 2004). Reid discusses the unique needs of direct-care staff who work with this population. He summarizes the performance- and competency-based behavioral skills training required for staff in these settings, along with a description of the skills that may warrant refined and sustained training. Among the recommendations Reid provides are meaningful activities incorporated into daily programming, teaching in a naturalistic manner, promoting happiness, and treating adults with dignity.

The goal of this Special Issue is to provide useful and practical tools for those who work with adolescents and young adults with ASD, as well as to promote future research with this population. Although the Special Issue covers a wide variety of topics, there are several other important areas that are not incorporated here. For example, there are a variety of issues related to employment that are important to consider for this population (Scott et al. 2019). Among these are specific programs to help prepare young adults, requesting workplace accommodations (Khalifa et al. 2019), enhancing job site training of supported employment (Lattimore et al. 2006), and assessing and teaching job-related social skills (Grob et al. 2019; Lora et al. 2019). In addition, topics related to sexuality are not specifically addressed in this Special Issue, although this is an area that has received increasing attention from the behavior-analytic community in recent years (Cividini-Motta et al. 2019; Davis et al. 2016). Combined, the papers presented here provide a meaningful contribution to the literature on adolescents and adults with ASD. They demonstrate the impact of assessment and treatment informed by behavior analysis when working with this population. This research also highlights the need for additional work in this area, not only with adolescents and young adults but also with aging adults with ASD who present with a host of new challenges such as decreased cognitive and physical abilities, which may further impact individuals and their caregivers. 


\section{Compliance with Ethical Standards}

Conflict of Interest The authors declare that they have no conflict of interest.

Ethical Approval Disclosure of statement about research involving human participants and/or animals and informed consent were not required for this manuscript.

\section{References}

Anderson, A. H., Stephenson, J., Carter, M., \& Carlon, S. (2019a). A systematic literature review of empirical research on postsecondary students with autism spectrum disorder. Journal of Autism and Developmental Disorders, 49(4), 1531-1558.

Anderson, C. M., Weddle, S. A., Walsh, M. L., \& Guglielmo, J. (2019b). Investigation of functional analysis methodology in adult service programs to develop efficient and effective treatment approaches. Advances in Neurodevelopmental Disorders, 3.

Bannerman, D. J., Sheldon, J. B., Sherman, J. A., \& Harchik, A. E. (1990). Balancing the right to habilitation with the right to personal liberties: the rights of people with developmental disabilities to eat too many doughnuts and take a nap. Journal of Applied Behavior Analysis, 23(1), 79-89. https://doi.org/10.1901/jaba.1990.23-79.

Bondy, A. (2019). Issues related to augmentative alternative communication and speech generating device use by adolescents and adults with autism spectrum disorder. Advances in Neurodevelopmental Disorders, 3.

Brazeau, K., Rehfeldt, R. A., Mazo, A., Smalley, S., Krus, S., \& Henson, L. (2017). On the efficacy of mindfulness, defusion, and behavioral skills training on job interviewing skills in dually diagnosed adults with developmental disorders. Journal of Contextual Behavioral Science, 6(2), 145-151.

Carnett, A., Hansen, S., McLay, L., Neely, L., \& Lang, R. (2019). Quantitative analysis of behavioral interventions to treat sleep problems in children with autism. Developmental Neurorehabilitation Advance online publication.

Centers for Disease Control and Prevention (2018). Data and statistics on autism spectrum disorder. Retrieved from: https://www.cdc.gov/ ncbddd/autism/data.html

Chen, J. L., Leader, G., Sung, C., \& Leahy, M. (2015). Trends in employment for individuals with autism spectrum disorder: a review of the research literature. Journal of Autism and Developmental Disorders, 2(2), 115-127. https://doi.org/10.1007/s40489-014-0041-6.

Cividini-Motta, C., Moore, K., Fish, L. M., Priehs, J. C., \& Ahearn, W. H. (2019). Reducing public masturbation in individuals with ASD: an assessment of response interruption procedures. Behavior Modification Advance online publication.

Davis, T. N., Machalicek, W., Scalzo, R., Kobylecky, A., Campbell, V., Pinkelman, S., et al. (2016). A review and treatment selection model for individuals with developmental disabilities who engage in inappropriate sexual behavior. Behavior Analysis in Practice, 9(4), 389402. https://doi.org/10.1177/1362361310393363.

Elias, R., \& White, S. W. (2018). Autism goes to college: understanding the needs of a student population on the rise. Journal of Autism and Developmental Disorders, 48(3), 732-746.

Gerhardt, P. F., \& Lainer, I. (2011). Addressing the needs of adolescents and adults with Autism: a crisis on the horizon. Journal of Contemporary Psychotherapy, 41(1), 37-45. https://doi.org/10. 1007/s10879-010-9160-2.

Gordon, K., \& Shillingsburg, A. (2019). Teaching mands for social information to individuals with developmental disabilities. Advances in Neurodevelopmental Disorders, 3.
Grob, C. M., Lerman, D. C., Langlinais, C. A., \& Villante, N. K. (2019). Assessing and teaching job-related social skills to adults with autism spectrum disorder. Journal of Applied Behavior Analysis, 52(1), $150-172$.

Hahler, E. M., \& Elsabbagh, M. (2015). Autism: a global perspective. Current Developmental Disorders Reports, 2(1), 58-64.

Hanley, G. P., Jin, C. S., Vanselow, N. R., \& Hanratty, L. A. (2014). Producing meaningful improvements in problem behavior of children with autism via synthesized analyses and treatments. Journal of Applied Behavior Analysis, 47(1), 16-36. https://doi.org/10.1002/ jaba.10.

Hedley, D., Uljarević, M., Cameron, L., Halder, S., Richdale, A., \& Dissanayake, C. (2017). Employment programmes and interventions targeting adults with autism spectrum disorder: a systematic review of the literature. Autism, 21(8), 929-941.

Hillier, A., Ryan, J., Donnelly, S., \& Buckingham, A. R. (2019). Peer mentoring to prepare high school students with autism spectrum disorder for college. Advances in Neurodevelopmental Disorders, 3.

Hollocks, M. J., Lerh, J. W., Magiati, I., Meiser-Stedman, R., \& Brugha, T. S. (2019). Anxiety and depression in adults with autism spectrum disorder: a systematic review and meta-analysis. Psychological Medicine, 49(4), 559-572.

Howlin, P., \& Moss, P. (2012). In review: adults with autism spectrum disorder. The Canadian Journal of Psychiatry, 57(5), 275-283.

Howlin, P., Magiati, I., \& Charman, T. (2009). Systematic review of early intensive behavioral interventions for children with autism. American Journal of Intellectual and Developmental Disabilities, 114(1), 23-41. https://doi.org/10.1352/2009.114:23.

Huffman, J. M., Bross, L. A., Watson, E. K., Wills, H. P., \& Mason, R. (2019). Demonstration of self-monitoring to support a college student with autism spectrum disorder. Advances in Neurodevelopmental Disorders, 3.

Hutchinson, V. D., Rehfeldt, R. A., Hertel, I., \& Root, W. B. (2019). Exploring the efficacy of acceptance and commitment therapy and behavioral skills training to teach interview skills to adults with Autism Spectrum Disorders. Advances in Neurodevelopmental Disorders, 3.

Iwata, B. A., Dorsey, M. F., Slifer, K. J., Bauman, K. E., \& Richman, G. S. (1994). Toward a functional analysis of self-injury. Journal of Applied Behavior Analysis, 27(2), 197-209. https://doi.org/10. 1901/jaba.1994.27-197.

Khalifa, G., Sharif, Z., Sultan, M., \& Di Rezze, B. (2019). Workplace accommodations for adults with autism spectrum disorder: a scoping review. Disability and Rehabilitation, 1-16.

Lattimore, L. P., Parsons, M. B., \& Reid, D. H. (2006). Enhancing job-site training of supported workers with autism: a reemphasis on simulation. Journal of Applied Behavior Analysis, 39(1), 91-102.

Lora, C. C., Kisamore, A. N., Reeve, K. F., \& Townsend, D. B. (2019). Effects of a problem-solving strategy on the independent completion of vocational tasks by adolescents with autism spectrum disorder. Journal of Applied Behavior Analysis Advance online publication.

Lotfizadeh, A. D., Kazemi, E., Pompa-Craven, P., \& Eldevik, S. (2018). Moderate effects of low-intensity behavioral intervention. Behavior Modification. Advance online publication. https://doi.org/10.1177/ 0145445518796204.

Maisel, M. E., Stephenson, K. G., Cox, J. C., \& South, M. (2019). Cognitive defusion for reducing distressing thoughts in adults with autism. Research in Autism Spectrum Disorders, 59, $34-45$.

Mutkins, E., Brown, R. F., \& Thorsteinsson, E. B. (2011). Stress, depression, workplace and social supports and burnout in intellectual disability support staff. Journal of Intellectual Disability Research, 55(5), 500-510. https://doi.org/10.1111/j.1365-2788.2011.01406.x.

National Autism Center. (2015). Findings and conclusions: national standards project, phase, 2. Randolph: Author Retrieved from http://www.nationalautismcenter.org/resources. 
Reichow, B., Hume, K., Barton, E. E., \& Boyd, B. A. (2018). Early intensive behavioral intervention (EIBI) for young children with autism spectrum disorders (ASD). The Cochrane Database of Systematic Reviews, 2018(5), CD009260. https://doi.org/10.1002/ 14651858.CD009260.pub3.

Reid, D. (2019). Training staff to provide quality support for adults with autism spectrum disorder: recommended practices and target skills. Advances in Neurodevelopmental Disorders, 3.

Reinders, N. J., Branco, A., Wright, K., Fletcher, P. C., \& Bryden, P. J. (2019). Scoping review: physical activity and social functioning in young people with autism spectrum disorder. Frontiers in Psychology, 10, 120.

Rosales, R., \& Whitlow, H. (2019). A component analysis of job interview training for young adults with autism spectrum disorder. Behavioral Interventions, 34(2), 147-162. https://doi.org/10.1002/ bin. 1658 .

Rose, D., Horne, S., Rose, J. L., \& Hastings, R. P. (2004). Negative emotional reactions to challenging behaviour and staff burnout: two replication studies. Journal of Applied Research in Intellectual Disabilities, 17(3), 219-223. https://doi.org/10.1111/j.1468-3148. 2004.00194.x.

Roth, M. E., Gillis, J. M., \& DiGennaro Reed, F. D. (2014). A metaanalysis of behavioral interventions for adolescents and adults with autism spectrum disorders. Journal of Behavioral Education, 23(2), $258-286$

Sanberg, S. A., Kuhn, B. R., \& Kennedy, A. E. (2018). Outcomes of a behavioral intervention for sleep disturbances in children with autism spectrum disorder. Journal of Autism and Developmental Disorders, 48(12), 4250-4277.

Scott, M., Milbourn, B., Falkmer, M., Black, M., Bölte, S., Halladay, A., et al. (2019). Factors impacting employment for people with autism spectrum disorder: a scoping review. Autism, 23(4), 869-901.

Szabo, T. (2019). Watch me try: an acceptance and commitment training approach to improving athletic performance of young adults with ASD. Advances in Neurodevelopmental Disorders, 3. van Deurs, J., McLay, L., France, K., Blampied, N., Lang, R., \& Hunter, J. (2019). Including adolescents with ASD in a behavioral sleep intervention: a pilot study. Advances in Neurodevelopmental Disorders, 3.

Van Hees, V., Moyson, T., \& Roeyers, H. (2015). Higher education experiences of students with autism spectrum disorder: challenges, benefits and support needs. Journal of Autism and Developmental Disorders, 45(6), 1673-1688.

Vanbergeijk, E., Klin, A., \& Volkmar, F. (2008). Supporting more able students on the autism spectrum: college and beyond. Journal of Autism and Developmental Disorders, 38(7), 1359-1370. https:// doi.org/10.1007/s10803-007-0524-8.

Volkmar, F. R., Jackson, S. L., \& Hart, L. (2017). Transition issues and challenges for youth with autism spectrum disorders. Pediatric Annals, 46(6), e219-e223.

Walsh, E. A., Holloway, J., Lydon, H., McGrath, A., \& Cunningham, T. (2019). An exploration of the performance and generalization outcomes of a social skills intervention for adults with autism and intellectual disabilities. Advances in Neurodevelopmental Disorders, 3.

White, S. W., Ollendick, T. H., \& Bray, B. C. (2011). College students on the autism spectrum: prevalence and associated problems. Autism, $15(6), 683-701$.

Wong, C., Odom, S. L., Hume, K. A., Cox, A. W., Fettig, A., Kucharczyk, S., et al. (2015). Evidence-based practices for children, youth, and young adults with autism spectrum disorder: a comprehensive review. Journal of Autism and Developmental Disorders, 45(7), 1951-1966.

World Health Organization (2018). Autism spectrum disorders. Retrieved from: https:/www.who.int/news-room/fact-sheets/detail/autismspectrum-disorders

Publisher's Note Springer Nature remains neutral with regard to jurisdictional claims in published maps and institutional affiliations. 